\title{
IMPROVING WATER RESISTANCE OF WHEAT STRAW-BASED MEDIUM DENSITY FIBERBOARDS BONDED WITH AMINOPLASTIC AND PHENOLIC RESINS
}

\author{
Thomas Hervillard $^{\mathrm{a}}$, Qi Cao ${ }^{\mathrm{b}}$ and Marie-Pierre G. Laborie ${ }^{\mathrm{b} *}$

\begin{abstract}
A long standing problem in the manufacture of wheat-straw based composites with cost-effective formaldehyde-based resins is their poor water resistance as demonstrated by their large water thickness swell. In this study, wheat straw based medium density fiberboards were manufactured using 3 resin/wax systems: a melamine-urea-formaldehyde resin with either low or high wax content, and a phenol-formaldehyde resin with low wax content. The flexural properties, internal bond strength, and thickness swell of the resulting composites were evaluated and compared according to ASTM methods. The three MDF composites passed the requirements for MDF in interior application, except for the MDF manufactured with the aminoplastic resin and low wax content that failed to provide acceptable thickness swell. Using the phenolic resin in combination with low wax content resulted in a higher grade MDF composite, grade 120, than with the aminoplastic and high wax content. This study demonstrates that wheat straw based MDF manufactured with cost-effective aminoplastic and phenolic resins can have flexural properties, internal bond strength and thickness swell performance above the requirements from the American National Standards Institute.
\end{abstract}

Keywords: Wheat Straw, Medium Density Fiberboard, Aminoplastic Resin, Phenolic Resin, Thickness Swell, ANSI for MDF

Contact information: a: Spie Batignolles TPCI, Service Expertises \& Structures, Pôle Magellan - Parc St Christophe, 95862 Cergy Pontoise Cedex, France; b: Wood Materials and Engineering Laboratory, Washington State University, Pullman, WA 99164, PO Box 641806, USA; *Corresponding author: mlaborie@wsu.edu

\section{INTRODUCTION}

The United States produces over 70 million tons (SI) of wheat straw residues (Kinsella 2004). Field burning is the most economic practice to dispose of these residues, but environmental pressure has resulted in increasingly stringent restrictions in the United-States. At the same time, the worldwide demand for fiberboards is predicted to double or triple from 1996 to 2010, creating a challenge to tumbling wood resources (Bowyer and Stockmann 2001). Increasing demands for fiberboards and depleted wood resources have therefore opened an opportunity for straw-based composites. As a result, intensive research and development have been conducted in the last decade to develop technology for manufacturing straw-based composites with thermosetting resins (Sauter 1996; Han et al. 2001b; Mantanis and Berns 2001; Wasylciw 2001; Mo et al. 2003) and more recently thermoplastic resins (Averous and Le Digabel 2006; Schirp et al. 2006). 
Technological and economical challenges have limited the commercialization of the straw-based composites with thermosetting resins (Lengel 2001). Polymeric methylene bis(phenylisocyanate), pMDI, an effective but expensive adhesive, has generally been used for manufacturing straw-based thermosetting composites. pMDI, which is currently used in the few strawboard plants in operation, is four times more expensive than aminoplastic resins and two times more than phenolic resins (Zhang et al. 2003; Mo et al. 2005).

Also, commercialization has focused on particleboards rather than medium density fiberboards (MDF), which is at odds with the reported adequacy of wheat straw for fiberbased materials (Sauter 1996; Hague et al. 1998; Lengel 2001). The refiners used for MDF manufacture offer opportunities to manipulate and optimize the straw properties for bonding (Hague et al. 1998; Grigoriou 2000).

For straw-based composites to be competitive, a MDF manufacturing technology that could use the more economical formaldehyde-based resins, urea-formaldehyde and/or phenol-formaldehyde, is needed. However, there are well-known technical challenges associated with bonding wheat straw with formaldehyde-based resins. First, wheat straw is covered with a waxy cuticle that inhibits adhesion with water-based adhesives. Second, wheat straw has a high buffering capacity that interferes with the hardening of aminoplastic resins (Sauter 1996). Previous studies have demonstrated that pressure refining lowers the straw acid buffering capacity and disintegrates the waxy cuticle, thereby affording better adhesion with urea-formaldehyde resins (Sauter 1996; Hague et al. 1998), albeit not to the levels required by the standards for MDF of the American National Standards Institute (American National Standards Institute 2002). Other pretreatments, including a chemi-thermomechanical treatment (Markessini et al. 1997), a twin-screw/pressure refining treatment (Mantanis and Berns 2001) or simply high-pressure refining (Han et al. 2001b; Wasylciw 2001; Wasylciw 2002) have also been shown to improve the adhesion of wheat straw fibers with UF or MUF resins. Straw-based composites could therefore be manufactured with UF resins to pass the ANSI requirements for internal bond strength and flexural properties (Han et al. 2001b; Mantanis and Berns 2001; Wasylciw 2001). More recently, enzymatic treatments have been reported to improve the properties of straw-based particleboards (Zhang et al. 2003).

In spite of the improvements imparted by these treatments, the water resistance and dimensional stability of straw-based MDF composites is still an issue. According to ANSI standards, the thickness swell of panels, with thickness between 9.5 and $15 \mathrm{~mm}$, should not exceed $1.5 \mathrm{~mm}$, whereas that of panels with thickness higher than $15 \mathrm{~mm}$ should not exceed 10\%. However, thickness swell values in the 20-30\% range have been repeatedly obtained (Markessini et al. 1997; Han et al. 2001b; Mantanis and Berns 2001), well above the allowance from the ANSI standard. To achieve acceptable water resistance, chemical modification of wheat straw has been performed prior to MDF manufacture with a phenolic resin and acetylated wheat straw (Gomez-Bueso et al. 2000). While efficient, the required chemical modification is expensive and impractical for industrial operations.

The objective of this research was to develop a simple technology to manufacture wheat-straw based MDF passing the minimum performance requirements for interior applications while using the low cost formaldehyde-based resins. In particular the 
research aimed at addressing the low dimensional stability and poor thickness swell performance of wheat-straw based composites. To that objective, the more waterresistant resins, melamine-urea-formaldehyde (MUF) and phenol-formaldehyde (PF) resins were selected for this research.

\section{EXPERIMENTAL}

\section{Materials}

Wheat straw, of the MADSEN variety, one of the most common varieties in the state of Washington, was provided by local farmers. The wheat straw was hammermilled into particles up to $5 \mathrm{~cm}$ long. The milled material was screened with a $0.5 \mathrm{~cm}$ screen to remove finer material. The straw was then soaked in cold water for 24 hours and processed in a disk refiner operating at atmospheric pressure and with spacing between the disks adjusted to $0.5 \mathrm{~mm}$. After refining the straw was dried to a moisture content of approximately $1 \%$ in a rotating drum dryer before hot-pressing.

Two formaldehyde-based resins were selected and utilized to develop strong water resistance. These were a Melamine-Urea-Formaldehyde (MUF) resin formulated and synthesized by Dynea and a Phenol-Formaldehyde (PF) resin from Hexion Specialty Chemicals. The MUF resin was formulated to provide water-resistance and consisted of $10 \%$ wt melamine based on solids at an overall $\mathrm{F} /(\mathrm{M}+\mathrm{U})$ molar ratio of 1.35 . The resin also was incorporated with an inorganic internal catalyst. The MUF resin had a nonvolatile solids content of $65.5 \%$, a $\mathrm{pH}$ of 8.4 , and a viscosity of $155 \mathrm{cps}$ at $25^{\circ} \mathrm{C}$. The base-catalyzed $\mathrm{PF}$ resin had a solids content of 51\%, a $\mathrm{pH}$ in the 11.5-12.5 range and a viscosity in the $80-180 \mathrm{cps}$ range at $25^{\circ} \mathrm{C}$. In addition, a wax emulsion, Coscowax EW $58 \mathrm{~S}$ was obtained from Hexion.

\section{Methods}

\section{Manufacture of straw-based MDF composites}

For each resin/wax combination, sufficient straw was refined to prepare three MDF panels of target density $850 \mathrm{~kg} / \mathrm{m}^{3}$ and dimensions $60 \times 60 \times 1 \mathrm{~cm}^{3}$. Three resin/wax combinations were selected to manufacture the MDF panels (Table 1). Based on dry wheat straw mass, these were: 1) $12 \%$ MUF resin content with $0.5 \%$ wax content, 2) $12 \%$ MUF resin with $1.5 \%$ wax content, and 3) $12 \%$ PF resin with $0.5 \%$ wax content.

Table 1. Parameters for MDF Manufacture Using 3 Resin/Wax Systems

\begin{tabular}{cc|ccccc|c}
\hline Resin & Wax & \multicolumn{5}{c|}{ Press cycle (sec) } & Press temperature \\
\hline \multicolumn{2}{c|}{$\begin{array}{c}\text { (\% solids on oven dry } \\
\text { straw) }\end{array}$} & $\begin{array}{c}\text { Press } \\
\text { Closing }\end{array}$ & $\begin{array}{c}\text { Resin } \\
\text { Cook }\end{array}$ & Degas & $\begin{array}{c}\text { Press } \\
\text { Open }\end{array}$ & Total & $\left({ }^{\circ} \mathrm{C}\right)$ \\
\hline MUF (12\%) & $0.5 \%$ & 45 & 345 & 30 & 60 & 480 & $160 \sim 166$ \\
MUF (12\%) & $1.5 \%$ & 45 & 345 & 30 & 60 & 480 & $160 \sim 166$ \\
PF (12\%) & $0.5 \%$ & 45 & 465 & 90 & 60 & 660 & 175 \\
\hline
\end{tabular}


Pretreated wheat straw fibers, resin, and wax were loaded in a rotary blender. During blending, straw packets or balls formed, which could cause homogeneity problems in the furnish mat. The straw packets were therefore eliminated by passing through a Nelmor hammer mill.

The furnish mixture was then homogeneously placed in a forming mold with dimensions $61 \times 61 \mathrm{~cm}^{2}$ by passing through a screen to even distribution. Panels were then hot-pressed in a $91 \times 91 \mathrm{~cm}^{2}$ computed-controlled hydraulic press with oil-heated platens. Hot-pressing conditions are outlined in Table 1. After pressing, the panels were cooled to ambient temperature and panel thickness measured with a caliper. Specimens for materials properties were then machined.

\section{Measurement of physical and mechanical properties}

Internal bond strength (IB), modulus of elasticity (MOE), modulus of rupture (MOR), and thickness swell (TS) were determined according to ASTM D 1037-99 (American Society for Testing Materials 2006a). For each test, sample size was determined a priori according to ASTM E 122-00 (American Society for Testing Materials 2006b) using properties estimates based on the literature (Grigoriou 2000). As a result, $18 \mathrm{IB}$ specimens, $9 \mathrm{MOE} / \mathrm{MOR}$ specimens and 9 TS specimens were prepared for each resin/wax combination from the three replicate boards. Dimensions for the test specimens were computed to be $50 \times 50 \times 10 \mathrm{~mm}^{3}$ for IB, $290 \times 76 \times 10 \mathrm{~mm}^{3}$ for flexural properties and $102 \times 102 \times 10 \mathrm{~mm}^{3}$ for thickness swell. While ASTM calls for larger TS specimens, smaller samples are commonly utilized and were deemed acceptable for comparison. The specimen cut-up pattern for each panel was designed in order to randomize specimen location (Figure 1).

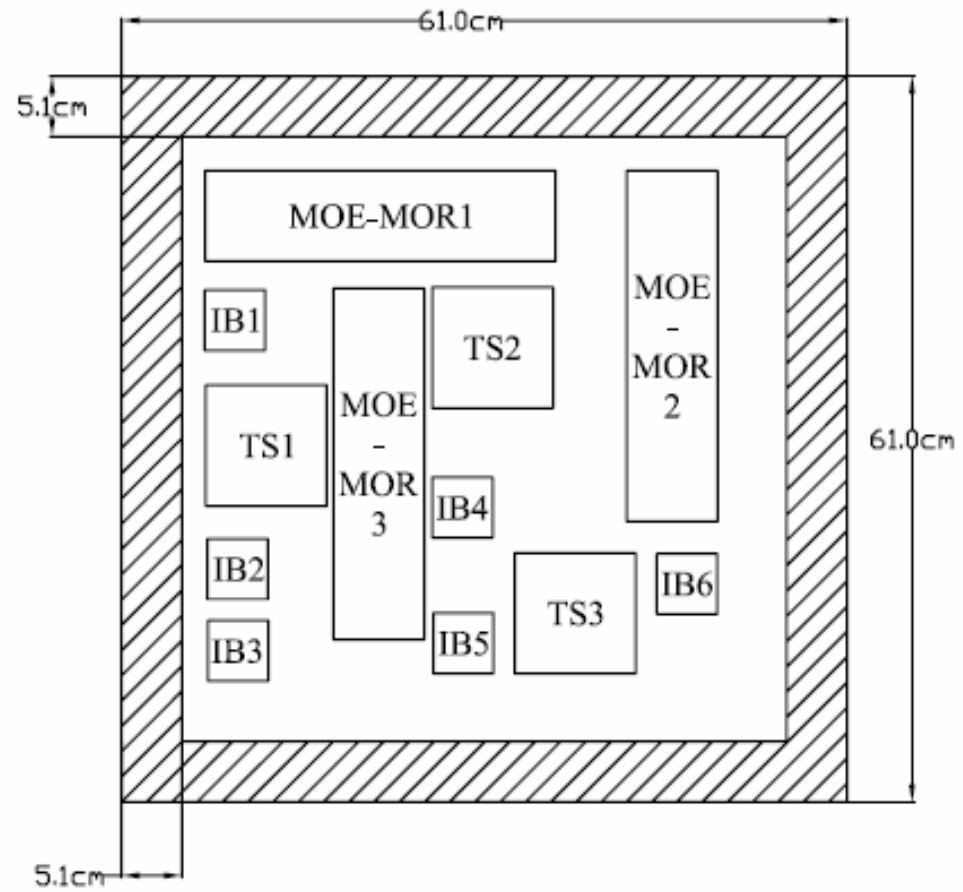

Fig. 1. Cut-up pattern for machining flexural (MOE-MOR), Internal bond (IB) and Thickness swelling (TS) specimens from each MDF panel. 
Before IB and flexural property measurements, the specimens were equilibrated for 72 hours in a conditioning room having $65.4 \% \pm 0.1 \%$ relative humidity and at $20^{\circ} \mathrm{C} \pm$ $3^{\circ} \mathrm{C}$. Weight and dimensions were measured on the IB specimens and the density was thus computed for each panel. In addition, the density profile was measured on the IB specimens using a QMS X-ray Density Profiler (Model QDP-01X. X-rays). Mechanical tests were performed on an INSTRON 4466. IB specimens were loaded at a crosshead speed of $0.78 \mathrm{~mm} / \mathrm{min}$. For flexural specimens, the loading rate was set at $0.47 \mathrm{~mm} / \mathrm{min}$ and the test span was $234 \mathrm{~mm}$. For thickness swelling test, the Method A, 2 Plus 22 hours submersion in water, of ASTM D 1037 was utilized. The measured properties for each of the three resin/wax combinations were compared to the requirements of the American national standard for MDF for interior applications. In addition, significant differences in the physical and mechanical properties measured for the three resin/wax combinations were detected by performing an ANOVA test at an $\alpha$ level of 0.1 , followed by a Tukey test.

\section{RESULTS AND DISCUSSION}

Wheat straw based MDF panels with densities in the $870-920 \mathrm{~kg} / \mathrm{m}^{3}$ range were successfully manufactured using the three resin/wax combinations, MUF/0.5\% wax, MUF/1.5\% wax, and with the PF/0.5\% wax. All the panels presented the typical density profile expected by mat densification. Namely, higher density was obtained near the panel face, while the core layer of the panel displayed a low density plateau (Figure 2).

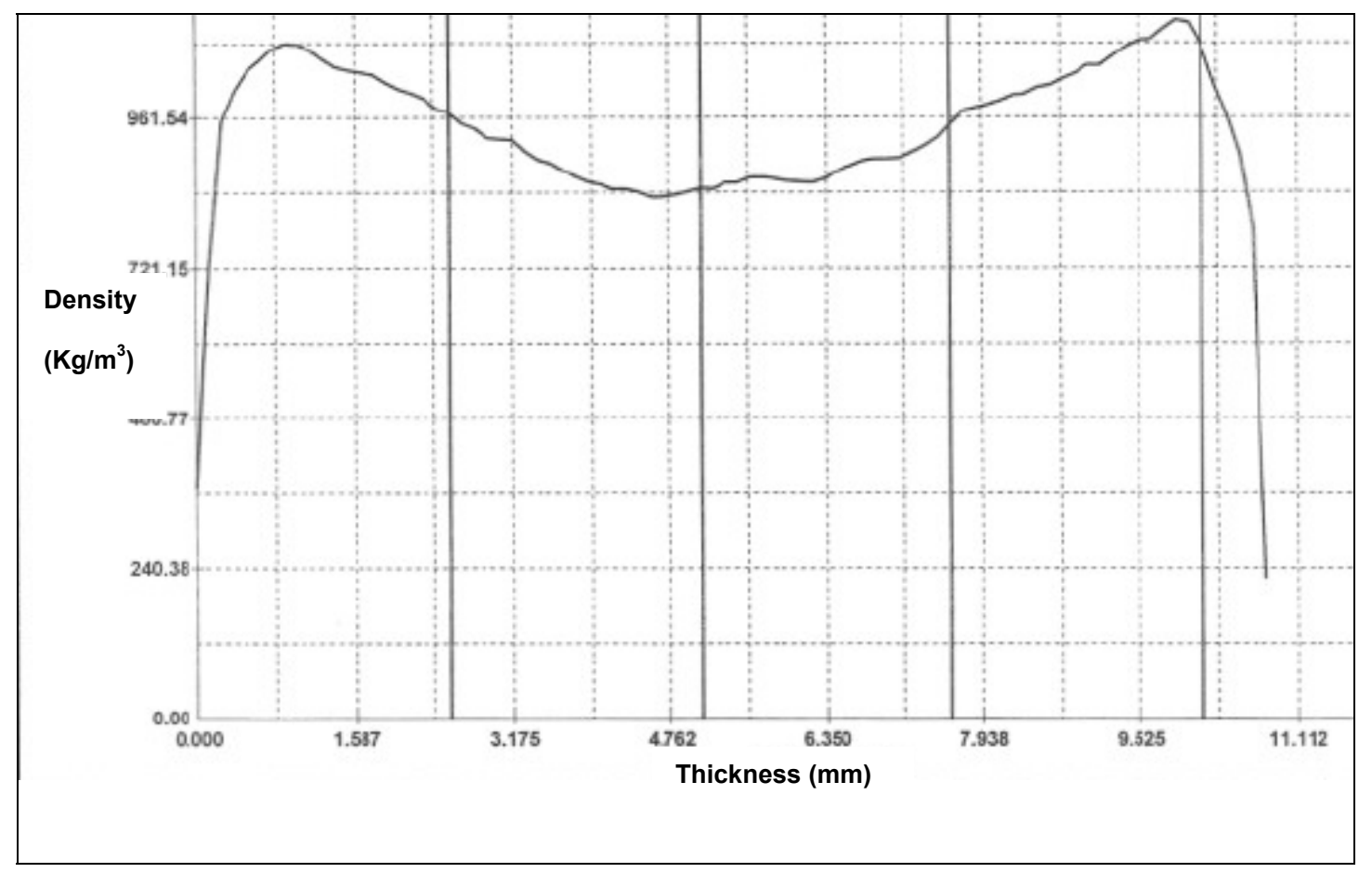

Fig. 2. Typical density profile of straw-based MDF boards 
Table 2 summarizes the properties of the composites manufactured with the three resin/wax systems. In this table, significant differences in properties detected from the ANOVA/Tukey tests are indicated with the letter grouping. In addition, the data obtained in this study are compared to those obtained by Han et al. (2001b) on wheat straw MDF manufactured with UF resins. These composites had a density of $700 \mathrm{~kg} / \mathrm{m}^{3}$ and were obtained after pressure steaming and refining of the fibers (Han et al. 2001b). Finally the overall MDF grade obtained from the ANSI specifications for each property is indicated in Table 2. MDF is classified as 110, 120, 130, 140, 150, and 160 grades, with the 160 grade representing the best properties.

Table 2. Physical and Mechanical Properties of $10 \mathrm{~mm}$ Thick Wheat Strawbased MDF

\begin{tabular}{c|cccccc|}
\cline { 2 - 6 } & $\begin{array}{c}\text { Density } \\
\left(\mathrm{kg} / \mathrm{m}^{3}\right)\end{array}$ & $\begin{array}{c}\text { MOE } \\
\left(\mathrm{N} / \mathrm{mm}^{2}\right)\end{array}$ & $\begin{array}{c}\text { MOR } \\
\left(\mathrm{N} / \mathrm{mm}^{2}\right)\end{array}$ & $\begin{array}{c}\text { IB } \\
\left(\mathrm{N} / \mathrm{mm}^{2}\right)\end{array}$ & $\begin{array}{c}\text { 24h TS } \\
(\mathrm{mm})\end{array}$ & $\begin{array}{c}\text { MDF } \\
\text { grade }\end{array}$ \\
\hline MUF, 0.5\% wax & $878 \pm 60$ & $3895 \pm 651$ & $33.1 \pm 2.7(\mathrm{~A})$ & $0.82 \pm 0.21(\mathrm{~A})$ & $1.7 \pm 0.4(\mathrm{~A})$ & - \\
MUF, 1.5\% wax & $915 \pm 44$ & $3773 \pm 440$ & $26.3 \pm 3.3(\mathrm{~B})$ & $0.44 \pm 0.05(\mathrm{C})$ & $0.9 \pm 0.1(\mathrm{~B})$ & $\mathbf{1 1 0}$ \\
PF, 0.5\% wax & $916 \pm 60$ & $3952 \pm 514$ & $32.4 \pm 4.0(\mathrm{~A})$ & $0.57 \pm 0.09(\mathrm{~B})$ & $1.0 \pm 0.3(\mathrm{~B})$ & $\mathbf{1 2 0}$ \\
Han et al. 2001 & $\sim 700$ & $\sim 2800$ & $\sim 32$ & $\sim 1$ & $>25 \%$ & - \\
\hline
\end{tabular}

$*(\mathrm{~A}),(\mathrm{B}),(\mathrm{C})$ indicates Tukey grouping when significant differences were detected

For all the straw-based MDF manufactured, very high flexural properties were obtained and were minimally influenced by the choice of the resin/wax system. Similar MOE values were obtained with the three resin/ wax systems, above $3100 \mathrm{~N} / \mathrm{mm}^{2}$, which corresponds to the requirement for the best MDF grade, 160 grade (American National Standard Institute 2002). High MOR values were also measured, with the MUF/0.5\% wax and the PF/ $0.5 \%$ wax systems ranking the best, again above the requirements for 160 grade MDF. When $1.5 \%$ wax was used in combination with the MUF resin, a lower MOR was obtained, but it still passed the grade 140 requirements for MDF. Altogether, the three resin/wax systems allowed for excellent flexural properties, which were likely related to the high density of the composites. These results are in line with previous work that measured high flexural properties in straw-based MDF (Grigoriou 2000; Han et al. 2001b; Mantanis and Berns 2001).

For internal bond strength, good values were also obtained with MDF manufactured with all 3 resin/wax systems, since all three passed the requirements for interior application. However, significant differences in IB were detected between the three resin/wax systems. The MUF resin in combination with $0.5 \%$ wax content performed best to a 140 grade MDF, above the PF/0.5\% wax system, achieving a 120 grade, and well above the MUF/1.5\% wax system, which reached a grade 110 . Altogether, satisfactory internal bond strengths were obtained with both aminoplastic and phenolic resins. These results confirm that adequate adhesion can be obtained between wheat straw and aminoplastic or phenolic resins after simple fiber refining. As previously demonstrated, fiber refining improves the bondability of wheat straw by removing the waxy cuticle on the wheat straw surface and also by reducing its acid buffering capacity (Sauter 1996; Hague et al. 1998). The lowest IB measured in the 
MUF/1.5\% wax system is likely due to the wax interfering with the adhesion between the MUF and wheat straw.

The resin/wax combinations were selected with a view to improving the thickness swell properties, which have not been satisfactory to date with wheat-based straw MDF. When comparing the 24 hours thickness swell for the three resin/wax systems, it was evident that high wax content afforded the best TS properties. With the MUF/1.5\% wax system, the composites had a low TS of $0.9 \mathrm{~mm}$, well below the maximum allowance of $1.5 \mathrm{~mm}$ and corresponding to less than $10 \%$ TS. The PF resin with only $0.5 \%$ wax content performed similarly as the MUF/1.5\% wax system within the ANSI requirements for MDF.

Phenol-formaldehyde resins are well known for their water-resistance and therefore are well suited to impart water resistance and low thickness swell properties to wheat-straw based composites even when used with low wax content. With the MUF resin on the other hand, high wax content must also be used to provide acceptable TS, since the MUF/0.5\% wax content did not pass the MDF requirements for interior applications with a large TS of $1.7 \mathrm{~mm}$. In the systems using MUF/1.5\% wax and $\mathrm{PF} / 0.5 \%$ wax, the average thickness swell was on the order of $10 \%$ maximum which was an improvement compared to previous reports of thickness swell of wheat straw-based MDF in the 20-30\% range (Grigoriou 2000; Han et al. 2001b).

Overall, MDF composites prepared with MUF/1.5\% wax and PF/0.5\% wax both passed the minimum requirements for flexural properties, internal bond strength and also thickness swell, with the PF resin providing the best grade of MDF composite, 120 grade. With the MUF/1.5\% wax system, the lowest MDF grade 110 was obtained overall. These results indicate that both MUF resins and PF resins could be used in combination with the appropriate wax content to manufacture wheat-straw based MDF composites that pass the ANSI requirements for interior applications, without resorting to expensive fiber modification (Gomez-Bueso et al. 2000; Han et al. 2001a). This is of significance because an impediment to the success of straw-based composites has been their low dimensional stability. Note that in this study the fiber preparation consisted of a simple refining step, suggesting that further improvement in physical and mechanical properties could be attained by optimizing the refining step using appropriate high-pressure conditions (Han et al. 2001b; Mantanis and Berns 2001).

\section{CONCLUSIONS}

1. Wheat straw-based MDF composites manufactured with aminoplastic and phenolic resins and appropriate wax contents passed the ANSI requirements for flexural properties, internal bond strength and also thickness swell for MDF used in interior applications.

2. The highest properties were achieved when a phenolic resin and a low wax content of $0.5 \%$ on wheat straw solids were used, resulting in a grade 120 straw-based MDF composite.

3. MDF composites bonded with a MUF resin and a wax content of $1.5 \%$ based on straw solids achieved a grade 110 .

Hervillard et al. (2007). "Fiberboard water resistance, resins," BioResources 2(2), 148-156. 154 
4. When wheat straw-based MDF composites were manufactured with a MUF resin in combination with low wax content of $0.5 \%$ on straw solids, the composites performed well above the standards for flexural and internal bond strength properties but failed to pass the ANSI requirement for thickness swell.

\section{ACKNOWLEDGMENTS}

This research was supported by the IMPACT (International Marketing Program for Agricultural Commodities and Trade) Center at Washington State University. The authors are thankful to Mark Anderson for specifically formulating a MUF resin for this project. The contribution of material from Hexion Specialty Chemicals is also acknowledged.

\section{REFERENCES CITED}

American National Standards Institute. (2002). ANSI A208.2-2002: Medium Density Fiberboard (MDF) for Interior Applications, Gaithersburg, MD, US.

American Society for Testing Materials. (2006a). ASTM D 1037-99: Standard test methods for evaluating properties of wood-base fiber and particle panel materials Philadelphia, PA.

American Society for Testing Materials. (2006b). ASTM E 122-00: Standard practice for calculating sample size estimate, with a specified tolerable error, the average for a characteristic of a lot or process Philadelphia, PA.

Averous, L., and Le Digabel, F. (2006). "Properties of biocomposites based on lignocellulosic fillers." Carbohydrate Polymers 66(4), 480-493.

Bowyer, J. L., and Stockmann, V. E. (2001). "Agricultural residues - An exciting biobased raw material for the global panels industry." Forest Products Journal 51(1), $10-21$.

Gomez-Bueso, J., Westin, M., Torgilsson, R., Olesen, P. O., and Simonson, R. (2000). "Composites made from acetylated lignocellulosic fibers of different origin - Part I. Properties of dry-formed fiberboards." Holz Als Roh-Und Werkstoff 58(1-2), 9-14.

Grigoriou, A. H. (2000). "Straw-wood composites bonded with various adhesive systems." Wood Science and Technology 34(4), 355-365.

Hague, J., McLauchlin, A., and Quinney, R. "Agri-materials for panel products: a technical assessment of their viability." $32^{\text {nd }}$ international particleboard/ composite materials symposium, Pullman, WA, 151-159.

Han, G. P., Umemura, K., Wong, E. D., Zhang, M., and Kawai, S. (2001a). "Effects of silane coupling agent level and extraction treatment on the properties of UF-bonded reed and wheat straw particleboards." Journal of Wood Science 47(1), 18-23.

Han, G. P., Umemura, K., Zhang, M., Honda, T., and Kawai, S. (2001b). "Development of high-performance UF-bonded reed and wheat straw medium-density fiberboard." Journal of Wood Science 47(5), 350-355. 
Kinsella, S. (2004). "Environmental paper listening study Chapter four: tree free paper (http://www.conservatree.org/paperlisteningstudy/TreeFree/question51.html)."

Lengel, D. E. "Ag-Fiber "Dot gone"- A litany of failure." $35^{\text {th }}$ international particleboard/ composite materials symposium, Pullman, WA, 125-132.

Mantanis, G., and Berns, J. "Strawboards bonded with urea formaldehyde resins." $35^{\text {th }}$ international particleboard/ composite materials symposium, Pullman, WA, 137-144.

Markessini, E., Roffael, E., and Rigal, L. "Panels from annual plant fibers bonded with urea-formaldehyde resins." $31^{\text {st }}$ international particleboard/ composite materials symposium, Pullman, WA, 147-160.

Mo, X. Q., Cheng, E. Z., Wang, D. H., and Sun, X. S. (2003). "Physical properties of medium-density wheat straw particleboard using different adhesives." Industrial Crops and Products 18(1), 47-53.

Mo, X. Q., Wang, D., and Sun, X. S. (2005). "Straw-based biomass and biocomposites." Natural fibers, biopolymers, and biocomposites, A. K. Mohanty, M. Misra, and L. T. Drzal, eds., Taylor \& Francis, Boca Raton, FL, 875 p.

Sauter, L. "Developing composites from wheat straw." 30th international particleboard/ composite materials symposium, Pullman, WA, 197-214.

Schirp, A., Loge, F. J., Englund, K. R., Wolcott, M. P., Hess, J. R., Houghton, T. P., Lacey, J. A., and Thompson, D. N. (2006). "Pilot-scale production and material properties of extruded straw-plastic composites based on untreated and fungal-treated wheat straw." Forest Products Journal 56(10), 90-96.

Wasylciw, W. "Straw-based composite panels- attributes, issues, and UF bonding technology." 35th international particleboard/ composite materials symposium, Pullman, WA, 145-153.

Wasylciw, W. (2002). "Methods of Straw fibre processing." C. Alberta Research Council, ed.

Zhang, Y., Lu, X., Pizzi, A., and Delmotte, L. (2003). "Wheat straw particleboard bonding improvements by enzyme pretreatment." Holz Als Roh-Und Werkstoff 61(1), 49-54.

Article submitted: Jan. 24, 2007; First-round reviews completed: February 13, 2007;

Revised version accepted: Feb. 23, 2007; Published Feb. 25, 2007 